\title{
MONITORING CROP YIELD IN USA USING A SATELLITE-BASED CLIMATE- VARIABILITY IMPACT INDEX
}

\author{
Ping Zhang ${ }^{1,2}$, Bruce Anderson ${ }^{3}$, Bin Tan ${ }^{1,2}$, Mathew Barlow ${ }^{4}$, Ranga Myneni ${ }^{3}$ \\ 1. Hydrospheric and Biospheric Science Laboratory, NASA's Goddard Space Flight Center, Greenbelt, MD, 20771, USA \\ 2. Earth Resource Technology Inc., Annapolis Junction, MD, 20701, USA \\ 3. Department of Geography, Boston University, Boston, MA, 02215, USA \\ 4. Environmental, Earth, and Atmospheric Sciences, University of Massachusetts Lowell, Lowell, MA, 01854, USA
}

\begin{abstract}
A quantitative index is applied to monitor crop growth and predict agricultural yield in continental USA. The ClimateVariability Impact Index (CVII), defined as the monthly contribution to overall anomalies in growth during a given year, is derived from 1-km MODIS Leaf Area Index. The growing-season integrated CVII can provide an estimate of the fractional change in overall growth during a given year. In turn these estimates can provide fine-scale and aggregated information on yield for various crops. Trained from historical records of crop production, a statistical model is used to produce crop yield during the growing season based upon the strong positive relationship between crop yield and the CVII. By examining the model prediction as a function of time, it is possible to determine when the in-season predictive capability plateaus and which months provide the greatest predictive capacity.
\end{abstract}

Index Terms - Remote Sensing, agriculture, image region analysis, modeling, GIS

\section{INTRODUCTION}

The interannual variations of crop yields are strongly affected by the environment and its variability. To get the pre-harvest information on crop yields, numerous crop growth simulation models are generated using crop state variables and climate variables at the crop/soil/water/atmosphere interfaces [1]. Most of these models require complex and detailed inputs to address the plant physiology process [2], soil water balance [3], as well as the interactions between soil and root systems [4]. In addition, plot-scale field experiments with specific soil types, water stress, nitrogen contents, and management processes are required for validation of the models [5].

A second type of yield forecast is based on data collected from farm operations and field observations, which require numerous time and labor in order to get a full sample size. In addition, these field studies have to be repeated frequently throughout the growing-season. The National Agricultural Statistics Service (NASS) monitors the crop conditions and yields via monthly-conducted Objective Yield Surveys in thousands of fields.

Since the early 1980s, vegetation indices derived from satellite data have been applied for crop monitoring and forecasting purposes. These indices include the ratio of the reflectance at near infrared to red, the Normalized Difference Vegetation Index (NDVI), Vegetation Condition Index (VCI), and the Climate-Variability Impact Index (CVII) derived from MODerate resolution Imaging Spectroradiometer (MODIS) Leaf Area Index (LAI) [6-10]. In general, these remotely-sensed metrics of vegetation activity have the following advantages: a unique vantage point, synoptic view, cost effectiveness, and a regular, repetitive view of nearly the entire earth's surface [11], thereby making them potentially better suited for crop monitoring and yield estimation at large scales.

We have previously demonstrated that the LAI-based CVII can quantify the percentage of the climatological annual production either gained or lost due to climatic variability and that it has a potential application in crop monitoring and yield estimation [9-10]. As a continuation of this effort, in this paper we will analyze the relationships between the CVII and crop yield using two case studies for a drought year in Illinois (2005) and a drought year in North and South Dakota (2006).

\section{DATA AND METHODOLOGY}

In this research, we used the $1-\mathrm{km}$ resolution MODIS LAI data, from 2000 to 2006, to generate the Climate-Variability Impact Index. The MODIS land cover map at $1-\mathrm{km}$ resolution was used to select broadleaf and cereal crop pixels. Crop production estimates are given at county- and state- levels by the U.S. Department of Agriculture. Accordingly, we aggregated LAI over the same regions by 


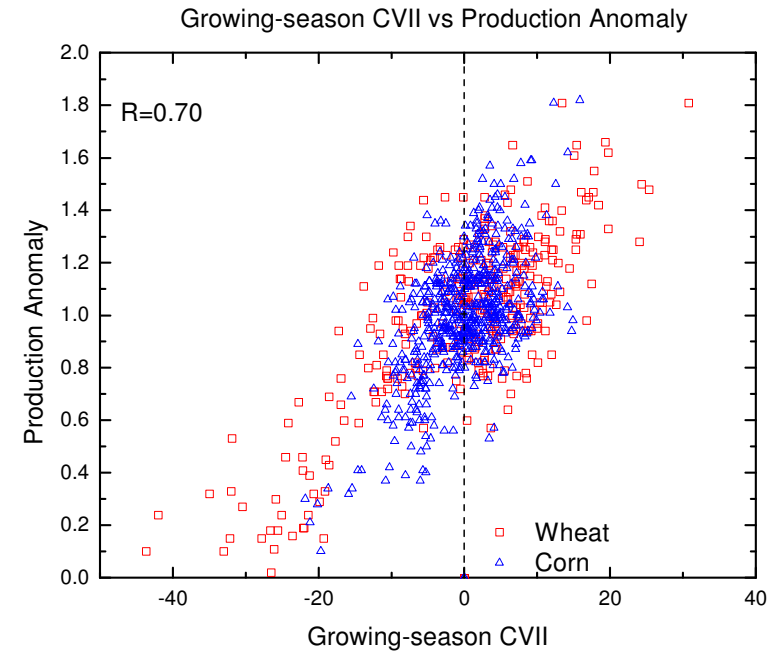

Fig. 1: Relationship between growing-season (Apr-Aug) CVII and crop production over the study regions of Illinois, South Dakota and North Dakota. MODIS landcover maps are used to select the cereal crops (wheat) and broadleaf crops (corn).

overlapping the LAI map with the county map and then calculated the Climate-Variability Impact Index for each county.

The Climate-Variability Impact Index (CVII), defined as the monthly contribution to anomalies in annual growth, quantifies the percentage of the climatological production either gained or lost due to climatic variability during a given month. For a given pixel p, let L(p,m,y) be the LAI in month $\mathrm{m}$ and year $\mathrm{y}, L^{\prime}(p, m)$ be the climatological LAI in month $\mathrm{m}$ and $\sum L^{\prime}(p)$ be the climatological annual LAI. The index $\operatorname{CVII}(p, m, y)$ in month $\mathrm{m}$ and year $\mathrm{y}$ is then calculated as :

$$
\text { CVII }(p, m, y)=100 \times \frac{L(p, m, y)-L^{\prime}(p, m)}{\Sigma L^{\prime}(p)}
$$

A strong positive correlation is found between the crop production and the CVII for counties in both Illinois and North and South Dakota [Fig. 1]. While the CVII increases from negative $40 \%$ to positive $40 \%$, the production anomaly increases from less than $10 \%$ to nearly $200 \%$ of the climatological mean. In general, fifty percent of the variance in crop production can be explained by the CVII.

To test whether the regression coefficients are strongly dependent on crop types in the different study regions and for the two different crop types, we fitted three linear models for the 2000-2004 CVII and production anomalies. The first model uses all the corn sample counties from the study regions. The second model uses all the wheat sample counties. The third model uses both corn and wheat sample counties. The $95 \%$ confidence intervals of the coefficients of the three models overlap, which indicates that these three linear models are not significantly different from each other [as shown in Table 1]. Our results demonstrate that the CVII-production relationship appears to be cropindependent for the study regions at county-level.

\section{RESULTS AND DISCUSSION}

\subsection{5 corn yield forecast at Illinois}

In the 2005 growing season, Illinois suffered an extreme drought condition and corn yields were predicted to be $30 \%$ less than the record year of 2004 by NASS. However, after most of the corn had been harvested by the end of October, the Illinois Agricultural Statistics Service indicated the overall corn yield is 145 bushels per acre, or $7 \%$ below the previous 5-year average.

In Figure 2, we compare the meteorological conditions represented by the 6-month SPI for March-August and the vegetative production represented by the integrated CVII map over the continental US in 2005 and 2002 (we show maps for 2002 because it had comparable crop losses to those expected in 2005 according to NASS). Focusing on Illinois, the 6-month SPI through the end of August indicates Illinois suffered a severe drought during the 2005 growing season, while conditions were slightly-above normal during 2002. However, the April-August integrated CVII maps for Illinois suggest a decrease in vegetation growth of only

\begin{tabular}{c|c|c|c|c|c|c}
\hline \multirow{2}{*}{ Model } & \multicolumn{2}{|c|}{ Unstandardized Coefficients } & \multirow{2}{*}{$\mathrm{t}$} & \multirow{2}{*}{ Sig. } & \multicolumn{2}{|c|}{ 95\% Confidence Interval } \\
\cline { 2 - 3 } \cline { 6 - 7 } & $\mathrm{B}$ & Std. Error & & Lower & Upper \\
\hline 1 Constant & 1.00 & 0.007 & 137.85 & $<.0001$ & 0.985 & 1.014 \\
CVII & 0.024 & 0.001 & 17.94 & $<.0001$ & 0.021 & 0.026 \\
\hline 2 Constant & 1.009 & 0.012 & 86.85 & $<.0001$ & 0.986 & 1.032 \\
CVII & 0.021 & 0.001 & 21.57 & $<.0001$ & 0.019 & 0.023 \\
\hline 3 Constant & 1.003 & 0.006 & 161.81 & $<.0001$ & 0.991 & 1.015 \\
CVII & 0.022 & 0.001 & 28.94 & $<.0001$ & 0.020 & 0.023 \\
\hline
\end{tabular}

Table 1: Linear Model between Crop Production (dependent) and Climate-Variability Impact Index (independent) at county Level. The first model is generated from corn counties. The second model is generated from wheat counties. The third model is generated both corn counties and wheat counties. 

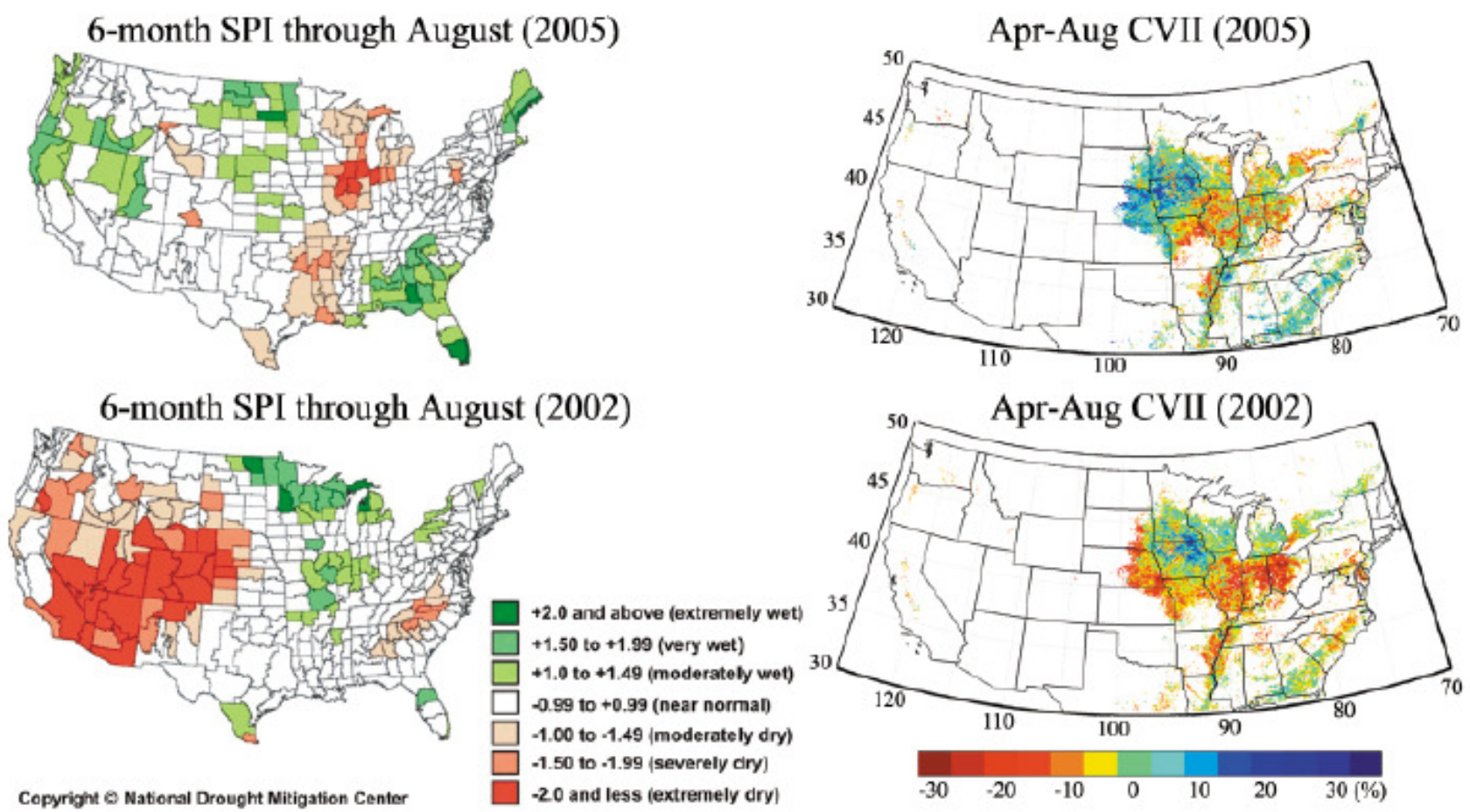

Fig. 2: 6-month Standardized Precipitation Index (SPI) vs. the growing-season Climate-Variability Impact Index (CVII) in 2002 and 2005. Six-month SPI maps are produced by National Drought Mitigation Center (http://www.drought.unl.edu/monitor/spi.htm). CVII values represent fractional loss (red) or gain (blue) of vegetation growth during the growing season (April-August), compared with the 2000-2004 mean. Only Broadleaf crops are shown.

about $10 \%$ in 2005 compared with a $10-20 \%$ decrease in 2002 [Fig. 2].

Although on a continental scale the CVII maps integrated over the growing season agree with the growing season water deficit conditions represented by 6-month SPI through August, our results highlight the need for explicit monitoring of vegetation growth when estimating yield. The case study in Illinois is particular demonstrates that droughtmonitoring indices based upon meteorological data alone, such as SPI, may miss important variability in vegetative production because they can both overestimate (2005) and underestimate (2002) impacts upon vegetation in droughtstricken regions [Fig. 2]. However, the CVII maps appear to have better success capturing the crop yield. The CVII model predicts a $7 \%$ decrease in 2005 corn yield in Illinois (compared to the previous 5 year average or 145 bushel/acre overall), which is almost identical to the actual state-wide corn yield from NASS released after the harvesting $(8 \%$ decrease, or 143 bushel/acre).

\subsection{Yield Forecast at North and South Dakota}

In 2006, the persistence of anomalous warmth made the summer the second warmest June-August period in the continental US in the past 110 years. An area stretching from south central North Dakota to central South Dakota is identified as drought-stricken, with the potential for significant crop loss according to the US drought monitor map released in August 2006. Using the CVII model, the 2006 corn and wheat production are predicted at county- and state-level in North and South Dakota. The model predicts a $23 \%$ decrease compared to the climatological mean in wheat and $4 \%$ decrease in corn, compared with the latest state-wide NASS estimates of $15 \%$ decrease in wheat and $1 \%$ increase in corn (released in November). While not as accurate as the 2005 predictions for Illinois, they actually represent a better prediction than the NASS September forecasts released concurrently with the CVII-based estimates

\subsection{Possibility of early yield forecast using CVII}

Because the satellite data used to derive the CVII are available in near real-time, satellite-based data can provide yield estimates before the end of the growing season. For instance, the forecast of $145 \mathrm{bushel} / \mathrm{acre}(7 \%$ decrease compared to the climatological mean) at Illinois was produced in mid-September, compared with the USDA's forecast of 136 bushel/acre at the same time, and the USDA's forecast of 145 bushel/acre released in October and 


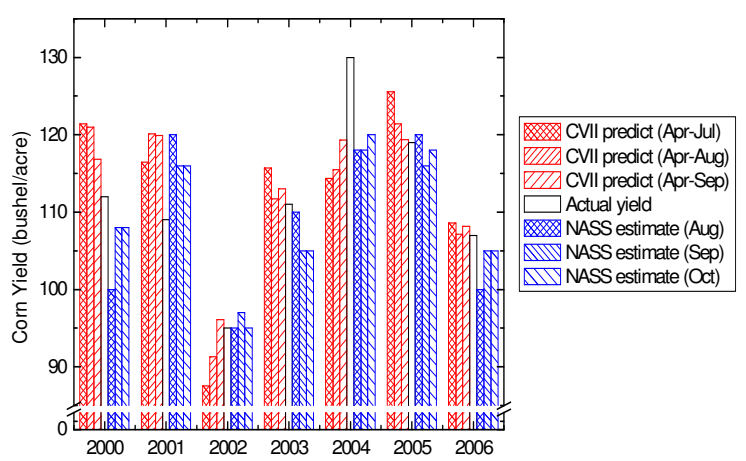

Fig. 3: The actual corn yield and the estimated yield in South Dakota made by NASS and CVII model over the course of the growing season. The NASS estimates (blue bars) are released in August, September and October for each year. The CVII model predictions (red bars) are based upon the CVII values at the end of July, August, and September. The actual yield is observed by NASS after harvesting.

November. As such, acceptable model forecasts of corn yield could be obtained at least one month prior to the end of the growing season due to the advantages of the satellite data. In the following, we examine the possibility of early forecast using our model.

Figure 3 shows the relationship between actual corn yield, NASS's forecasts released in August, September and October, and our model predictions made during July, August, and September using CVII for South Dakota from 2000 to 2006. The model predictions based on integrated CVII have a typical lag of approximately 2 week. As such, the April-July/August/September integrated CVII predictions are concurrent with the NASS estimates released in August/September/October respectively. The actual corn yield of South Dakota is estimated by NASS after harvesting in each year and is used as the actual yield for the given year. The in-season CVII model shows predictability comparable to the concurrent NASS estimates [Fig. 3]. For instance, in mid-August 2006 the CVII model predicted a corn yield of 108 bushel/acre for South Dakota, which is almost identical to the actual yield of 107 bushel/acre. In comparison, the NASS estimate released in August predicted a yield of 100 bushel/acre and in October predicted a 105 bushel/acre.

While the satellite-based estimates of yield are not necessarily a substitute for those provided by ground-based methods (as done by agricultural services for instance), satellites can provide a secondary, independent estimate that can pinpoint regions where agricultural failure is greatest. Overall, the high temporal and spatial resolution as well as the availability of the timely access to the needed MODIS products makes CVII a useful tool for near real-time crop monitoring and yield forecasts before harvesting. More importantly, the cost effectiveness and repetitive, near- global view of earth's surface suggest this LAI-based CVII may significantly improve crop monitoring and yield estimation at regional scales. Furthermore, with inclusion of fine temporal resolution MODIS data, future applications of the 8-day and 16-day CVII maps may provide detailed crop monitoring at different growth stages and provide earlier warning signals.

\section{REFERENCES}

[1] J.L. Monteith, "Climate and the efficiency of crop production in Britain", Philosphical transactions of the Royal Society of London. Ser. B, 277-294, 1977.

[2] R.G. Allen, L.S. Pereira, D. Raes, and M. Smith, "Crop Evapotranspiration - Guidelines for Computing Crop Water Requirements" - FAO Irrigation and Drainage Paper 56, Food and Agriculture Organization, Rome, Italy. pp 145-167, 1998.

[3] A.R. Sepaskhah, A.R. Bazrafshan-Jahromi, and Z. Shirmohammadi-Aliakbarkhani, "Development and Evaluation of a Model for Yield Production of Wheat, Maize and Sugarbeet under Water and Salt Stresses," Biosystems Engineering 93 (2), pp 139-152, 2006.

[4] S. Zand-Parsa, and A. Ronaghi," Development and evaluation of integrated water and nitrogen model for maize." Agricultural Water Management, 81(3), pp 227-256, 2006.

[5] A.A. Boling, B.A.M. Bouman, T.P. Tuong, M.V.R, Murty, S.Y. Jatmiko, "Modelling the effect of groundwater depth on yieldincreasing interventions in rainfed lowland rice in Central Java, Indonesia," Agricultural Systems, 92, pp. 115-139, 2007.

[6] B.F.T. Rudorff, and G.T. Batista, "Yield estimation of sugarcane based on agrometeorological-spectral models," Remote Sensing of Environment, 33, pp. 183-192, 1990.

[7] K.P. Hochheim, and D.G. Barber, "Spring wheat yield estimation for western Canada using NOAA NDVI data," Canadian Journal of Remote Sensing, 24(1), pp. 17-27, 1998.

[8] F.N. Kogan, "Droughts of the late 1980s in the United States as derived from NOAA polar-orbiting satellite data," Bull. Amer. Meteor. Soc., 76, pp. 655-668, 1995.

[9] P. Zhang, B. Anderson, B. Tan, D. Huang, R. Myneni, "Potential Monitoring of Crop Production Using a Satellite-Based Climate-Variability Impact Index," Agricultural and Forest Meteor, 132, pp. 344-358, 2005.

[10] P. Zhang, B. Anderson, R. Myneni, "Monitoring 2005 Corn Belt Yields from Space", EOS, Transactions, American Geophysical Union,VOL. 87, No. 15, pp.150, 11th April, 2006.

[11] G.E. Johnson, V.R. Achutuni, S. Thiruvengadachari, F. Kogan, "The role of NOAA satellite data in drought early warning and monitoring: selected case studies," in Drought Assessment, Management, and Planning: Theory and Case Studies, edited by D. A. Wilhite, pp. 31-49. Kluwer Academic, 1993. 